\title{
Editorial
}

\section{Mathematical Modeling in Virology by Differential Equations}

\author{
Khalid Hattaf $\mathbb{D}^{1},{ }^{1}$ Ahmed M. Elaiw $\mathbb{D}^{1},{ }^{2}$ Abid A. Lashari, ${ }^{3}$ and Noura Yousfi $\mathbb{D}^{4}$ \\ ${ }^{1}$ Centre Régional des Métiers de l'Education et de la Formation (CRMEF), 20340 Derb Ghalef, Casablanca, Morocco \\ ${ }^{2}$ Department of Mathematics, Faculty of Science, King Abdulaziz University, Jeddah, Saudi Arabia \\ ${ }^{3}$ Department of Mathematics, Stockholm University, 10691 Stockholm, Sweden \\ ${ }^{4}$ Laboratory of Analysis, Modeling and Simulation (LAMS), Faculty of Sciences Ben M'sik, Hassan II University, \\ P.O. Box 7955 Sidi Othman, Casablanca, Morocco \\ Correspondence should be addressed to Khalid Hattaf; k.hattaf@yahoo.fr
}

Received 27 March 2018; Accepted 28 March 2018; Published 3 May 2018

Copyright (C) 2018 Khalid Hattaf et al. This is an open access article distributed under the Creative Commons Attribution License, which permits unrestricted use, distribution, and reproduction in any medium, provided the original work is properly cited.

Viruses are microscopic organisms that need to penetrate inside a cell of their host to multiply and replicate. Various viruses infect directly the human body such as the human immunodeficiency virus (HIV), hepatitis B virus (HBV), and hepatitis $\mathrm{C}$ virus (HCV). There are also viruses that affect the human body through a living vector such as West Nile virus which is a virus most commonly spread to people by mosquito bites. Infectious diseases caused by these viruses represent a major global health problem by causing mortality of millions of people and expenditure of enormous amount of money in health care and disease control. In this special issue, many mathematical models, ordinary differential equations (ODEs), delay differential equations (DDEs), partial differential equations (PDEs), and fractional differential equations (FDEs), have been proposed and developed to better describe the dynamics of these infectious diseases and establish control strategies to limit their evolution and spread.

One paper of this special issue proposes a mathematical model with ODEs and PDEs to describe the dynamics of vector-borne diseases such as West Nile virus, malaria, and dengue. The proposed model incorporates the waning of vaccine-induced immunity. Furthermore, the global stability of the equilibria of the model is established. More precisely, it is proved that when the basic reproduction number is less than one, the disease-free equilibrium is globally asymptotically stable, which implies that the disease dies out. However, when the basic reproduction number is larger than one, the endemic equilibrium is globally asymptotically stable, which means that the disease persists in the population.

Another paper presents a delayed model formulated by DDEs in order to study the early stage of HBV infection and impact of the delay in the infection process on the adaptive immune response, which includes cytotoxic $\mathrm{T}$ lymphocytes (CTL) cells and antibodies. The stability analysis of equilibria and the optimal treatment strategies are investigated.

Another paper focuses on the qualitative analysis of a generalized virus dynamics model with distributed delays and two modes of transmission, one by virus-to-cell infection and the other by cell-to-cell transmission. The infection transmission process is modeled by general incidence functions for both modes of transmission. Moreover, many known viral infection models with discrete and distributed delays are extended and improved.

Another paper deals with a family of periodic SEIRS epidemic models. The global dynamics of these models is fully determined by a threshold parameter, namely, the basic reproduction number. Numerical simulations are carried out to support the theoretical results.

Another paper of this special issue proposes a fractional order model of HIV infection with specific functional response and cure rate. This functional response covers the most functional responses used by several authors such as the saturated incidence rate, the Beddington-DeAngelis functional response, and the Crowley-Martin functional 
response. It is shown that the model is mathematically and biologically well-posed. In addition, the local and global stabilities of the equilibria are investigated.

Khalid Hattaf Ahmed M. Elaiw Abid A. Lashari Noura Yousfi 


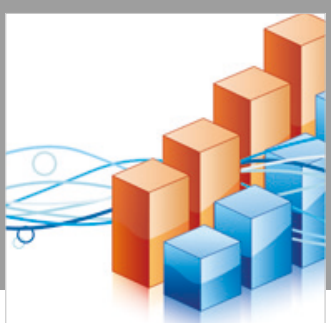

Advances in

Operations Research

\section{-n-m}
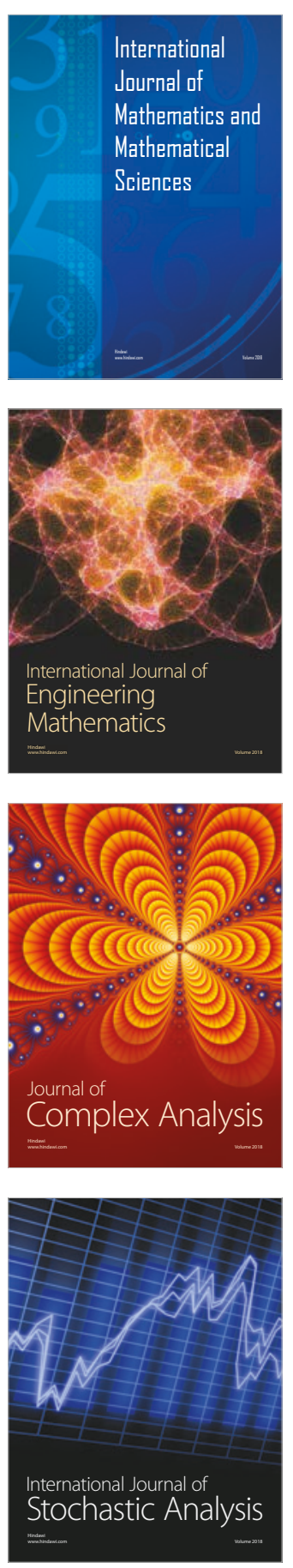
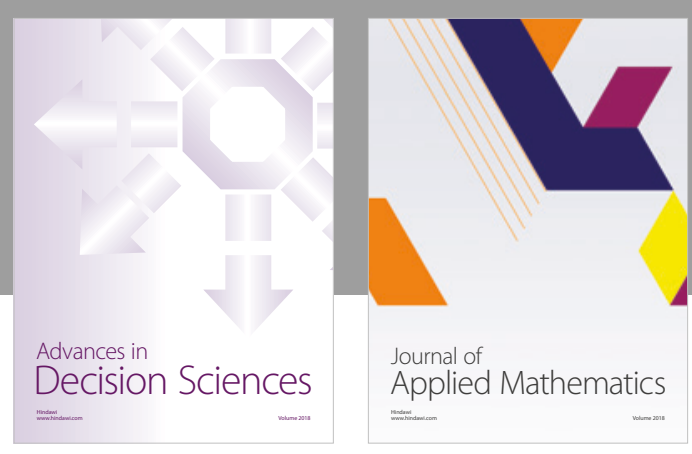

Journal of

Applied Mathematics
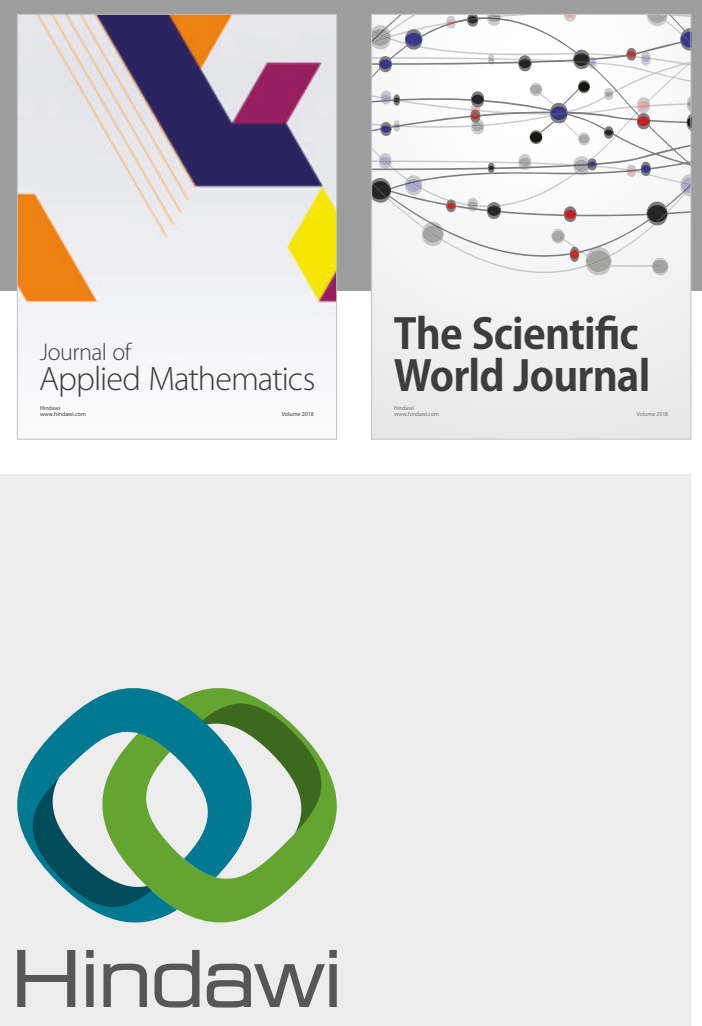

Submit your manuscripts at

www.hindawi.com

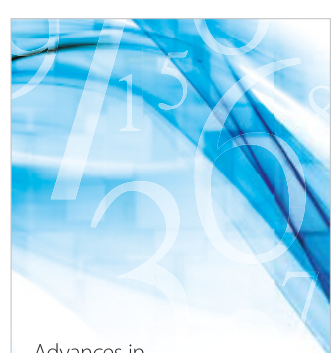

Advances in
Numerical Analysis
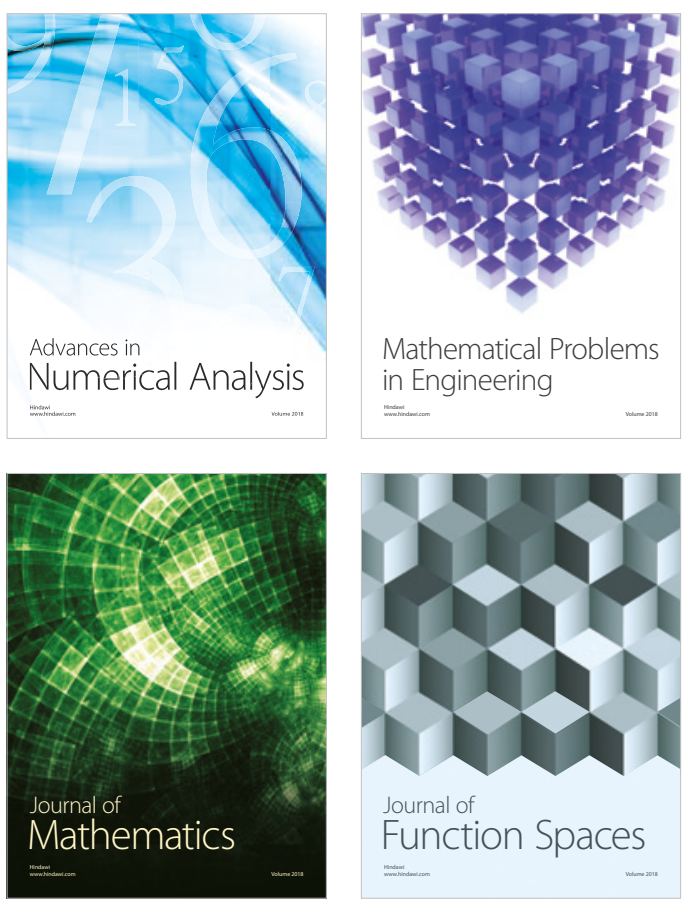

Mathematical Problems in Engineering

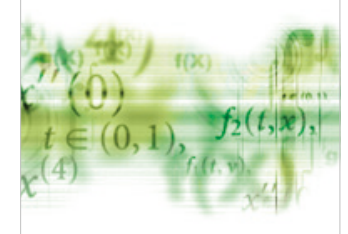

International Journal of

Differential Equations

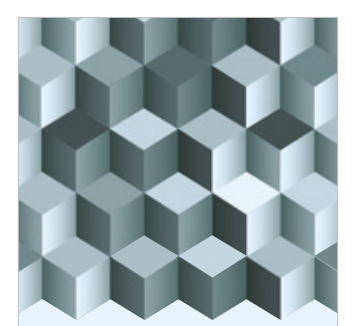

Journal of

Function Spaces

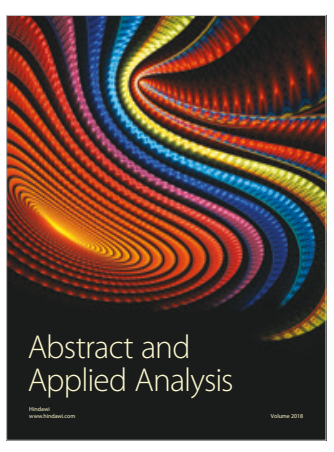

The Scientific

World Journal

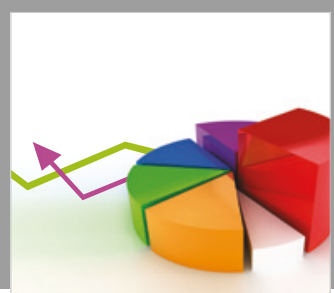

Journal of

Probability and Statistics
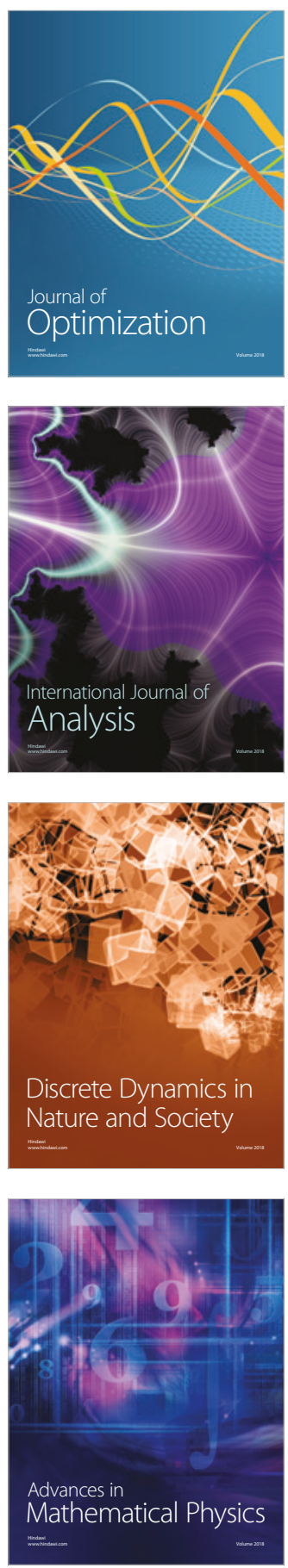